\title{
FASILITAS PENGGEMAR PAKAIAN EKONOMIS
}

\author{
Alvin $^{1)}$, Mieke Choandi ${ }^{2)}$ \\ 1)Program Studi S1 Arsitektur, Fakultas Teknik, Universitas Tarumanagara, alvinshb@yahoo.com \\ 2)Program Studi S1 Arsitektur, Fakultas Teknik, Universitas Tarumanagara, miekec@ft.untar.ac.id
}

\begin{abstract}
Abstrak
Seiring perkembangannya zaman, masyarakat khususnya di perkotaan cenderung memiliki sifat yang individualis dikarenakan rutinitas sehari-hari yang padat. Dimana sebagian besar waktu dihabiskan di tempat kerja, rumah ataupun pusat perbelanjaan. Manusia sebagai makhluk sosial yang seharusnya bersosialisasi dan berinteraksi dengan sesama untuk memenuhi kebutuhan sosial. Untuk memenuhi kebutuhan sosial di era modern saat ini, dibutuhkan wadah sosial yang dapat menampung aktivitas-aktivitas masyarakat sekitar. Sehingga masyarakat dapat saling bertemu, bersosialisasi dan juga berinteraksi melalui media wadah sosial tersebut. Jakarta Pusat, tepatnya di Kawasan Senen, terdapat Pasar Senen yang merupakan salah satu bangunan yang bersejarah / ikonik yang dikenal sebagai tempat yang padat akan aktivitas berniaganya yaitu perdagangan / jasa yaitu Pasar Senen, dikenal sebagai pusat thrift di Jakarta saat ini yaitu pusat masyarakat dapat mencari pakaian dengan harga yang ekonomis. Akan tetapi keseharian masyarakat Senen cenderung hanya menjual pakaian saja membuat jenuh masyarakat Senen sehingga Pasar Senen kini meredup. Serta Senen terdapat minim sekali tempat hiburan yang terdapat di Kawasan Senen sehingga menimbulkan perekonomian Senen menurun. Hal ini berkaitan juga dengan teori dari Malcolm Barnard bahwa pakaian dapat menjadi sebuah alat komunikasi baik verbal maupun non-verbal yang nantinya dapat memulihkan kembali kawasan Senen menjadi Kawasan yang masyarakatnya tidak berdagang saja akan tetapi dapat berinteraksi, bersosialisasi, serta mengasah kreatifitas dari Fasilitas Penggemar Pakaian Ekonomis. Dimana Proyek ini bertujuan untuk menunjang Pasar Senen juga mengurangi kejenuhan penghuni Pasar Senen dalam kegiatan berniaganya sehari-hari juga untuk memfasilitasi kebutuhan pengguna jasa di Stasiun Bus Senen. Proyek ini juga ditujukan sebagai wadah bagi komunitas-komunitas thrift maupun seni sekitar untuk berinteraksi dengan komunitas lainnya dan juga dapat menunjukan karya-karya / sejarah dari pakaian ekonomis yang masyarakat akan lihat dan beli sehingga tidak hanya berdagang saja, akan tetapi masyarakat dapat mempelajari dan memahami arti dari pakaian tersebut yang akhirnya memicu masyarakat untuk berinteraksi, bersosialisasi, serta mengasah kreatifitas mereka.
\end{abstract}

Kata kunci: pakaian; Pasar Senen; thrift

\begin{abstract}
As time goes by, people, especially in urban areas, tend to have individualistic characteristics due to their busy daily routines. Where most of the time spent at work, home or shopping centers. Humans as social creatures who should socialize and interact with others to meet social needs. To meet social needs in the current modern era, it takes a social container that can accommodate the activities of the surrounding community. So that people can meet with each other, socialize and also interact through these social media platforms. Central Jakarta, precisely in the Senen Area, there is the Senen Market which is one of the historic / iconic buildings known as a dense place for trade activities, namely trade / services, namely the Senen Market, known as the Thrift center in Jakarta today, the community center can search clothes at economical prices. However, the daily life of the Senen people tends to only sell clothes that saturate the Senen community so that the Senen Market is now fading. As well as Senen, there are very few entertainment venues in the Senen Region, causing the Senen economy to decline. This is also related to
\end{abstract}


Malcolm Barnard's theory that clothing can be a verbal and non-verbal communication tool that can later restore Senen area to an area where people do not trade but can interact, socialize, and hone the creativity of the Clothing Fan Facility Economical. Where this project aims to support the Senen Market also reduces the saturation of the Senen Market residents in their daily business activities as well as to facilitate the needs of service users at the Senen Bus Station. This project is also intended as a forum for Thrift communities and the surrounding arts to interact with other communities and can also show the works / history of economic clothing that people will see and buy so that not only trading, but the public can learn and understand the meaning of the clothes which finally triggers the community to interact, socialize, and hone their creativity.

Keywords: clothing; Pasar Senen; Thrift

\section{PENDAHULUAN} Latar Belakang

Dengan berkembangnya zaman, masyarakat khususnya di perkotaan cenderung memiliki sifat yang individualistis dikarenakan rutinitas sehari-hari yang padat. Dimana sebagian besar waktu mereka dihabiskan di tempat kerja, rumah ataupun pusat perbelanjaan. Manusia adalah makhluk sosial yang seharusnya bersosialisasi dan berinteraksi dengan satu sama lain untuk memenuhi kebutuhan sosialnya.

Untuk memenuhi kebutuhan sosial di era modern saat ini, dibutuhkan wadah sosial yang dapat menunjang aktivitas-aktivitas masyarakat sekitar. Sehingga masyarakat dapat saling bersosialisasi dan juga berinteraksi melalui media wadah sosial tersebut. Senen merupakan kawasan yang padat akan aktivitas nya sehari-hari yaitu berdagang dan jasa. Khususnya Pasar Senen yang merupakan salah satu bangunan yang memiliki nilai sejarah yang kuat bagi masyarakat Senen maupun kota Jakarta dan merupakan pusat thrift fashion perdagangan / jasa yang besar di Jakarta saat ini. Dengan aktivitas yang padat setiap hari nya, Senen memiliki minim sekali tempat hiburan yang dapat mengurangi kejenuhan kegiatan berniaga masyarakatnya sehari-hari. Produktivitas di Senen yang tinggi akan tetapi tidak sebanding dengan entertainment-nya maka lama kelamaan perekonomian di Senen pun menurun.

Hal ini ditandai dengan Pasar Senen yang tadinya sangat ramai akan pengunjung lama kelamaan Pasar Senen sendiri tidak lagi banyak dikunjungi karena telah terdapat pusat perbelanjaan yang besar di Jakarta. Dikarenakan tidak diimbangi dengan aktivitas-aktivitas yang dapat menarik masyarakat. Maka dari itu dibutuhkan sebuah tempat untuk mendukung agar dapat mewadahi kegiatan berniaga masyarakat Senen setiap hari nya juga dapat menarik pengunjung luar Senen untuk datang sehingga terjadi interaksi antar masyarakat yang dapat memicu perkembangan Senen.

\section{Rumusan Permasalahan}

Rumusan masalah yang timbul pada proyek ini adalah bagaimana proyek Fasilitas Penggemar Pakaian Ekonomis ini dapat menjadi "The Thrid Place" bagi masyarakat di Senen, Bagaimana proyek Fasilitas Penggemar Pakaian Ekonomis ini dapat memicu timbulnya interaksi sosial antar masyarakat Senen maupun luar Senen ? dan Program apa saja yang dibutuhkan untuk menunjang aktivitas para pengguna Pasar Senen?

\section{Tujuan}

Proyek ini bertujuan untuk mengurangi kejenuhan penghuni Pasar Senen dalam kegiatan berniaganya sehari-hari juga untuk memfasilitasi kebutuhan pengguna jasa di Stasiun Bus Senen. Keberadaan proyek ini selain menunjang Thriftshop Pasar Senen yang sudah dikenal oleh masyarakat juga menambahkan berbagai aktivitas yang ada di sekitarnya agar semakin 
bertambah ramai dan hidup. Karena proyek ini ditujukan bagi seluruh lapisan masyarakat pengguna, menjawab esensi dari Third Place sebagai ruang netral bagi seluruh lapisan masyarakat Senen khususnya dan masyarakat kota Jakarta umumnya

\section{KAJIAN LITERATUR}

Kajian literatur membahas tentang teori-teori yang berhubungan dengan konsep proyek yang akan dibangun, seperti teori Ray Oldenburg yang membahas karakteristik Thrid Place, Malcolm Barnard membahas tentang fashion sebagai alat komunikasi, dan Edwards yang membahas tentang stress dan kecemasan.

\section{Ray Oldenburg "The Great Good Place (Third Place)"}

Ray Oldenburg dalam bukunya yang berjudul "The Great Good Place (Third Place)" mengatakan bahwa Third Place / tempat ketiga merupakan tempat yang penting bagi masyarakat sipil, demokrasi, keterlibatan sipil dan membangun perasaan rasa tempat. Dimana tempat pertama (First Place) merupakan rumah tempat tinggal dan tempat kedua (Second Place) adalah tempat kerja dimana orang mungkin menghabiskan sebagian besar waktu mereka. The Third Place juga merupakan sebuah tempat Informal yang dijadikan sebagai tempat untuk berkumpul, berinteraksi, dan bersosialisasi antara sesama manusia dengan tujuan agar manusia dapat menjadi pribadi yang lebih humanis dan peduli akan sesamanya.

\section{Malcolm Barnard "Fashion as Communication"}

Konsep Fashion / Pakaian dapat menjadi sebuah alat komunikasi baik secara verbal maupun non -verbal yang nantinya akan disampaikan ke setiap pribadi manusia sebagai perantara untuk membuat pribadi manusia itu sendiri berubah menjadi kearah yang lebih positif dan melatih pola berfikir manusia untuk lebih kreatif. Tidak hanya merubah tapi dapat juga sebagai pesan yang ingin disampaikan kepada lingkungannya dalam bentuk pengekspresian diri terhadap mood yang sedang dialami pribadi manusia pada saat hari itu dan kondisi lingkungan sekitar yang dikunjunginya.

\section{Edwards "Measuring Compulsive Buying Behaviour"}

Dari teori Edward ini mengatakan bahwa sebenarnya dengan berbelanja kita sebagai pribadi manusia dapat menghilangkan rasa perasaan negatif yaitu stress / perasaan cemas, akan tetapi dengan berbelanja yang berlebihan pastinya akan membuat pribadi manusia menjadi rusak / merasa kecanduan. Dimana bukannya memperbaiki pribadi manusia sendiri lebih baik malah mengarah ke hal yang negatif. Oleh karena itu dalam Third Place nanti yang dirancang harus memiliki lingkungan sosial yang baik serta diberikan edukasi dan pemahaman agar masyarakat dibimbing dan dipandu untuk meningkatkan kualitas hidup individu masyarakat di area Third Place nanti. 


\section{METODE}

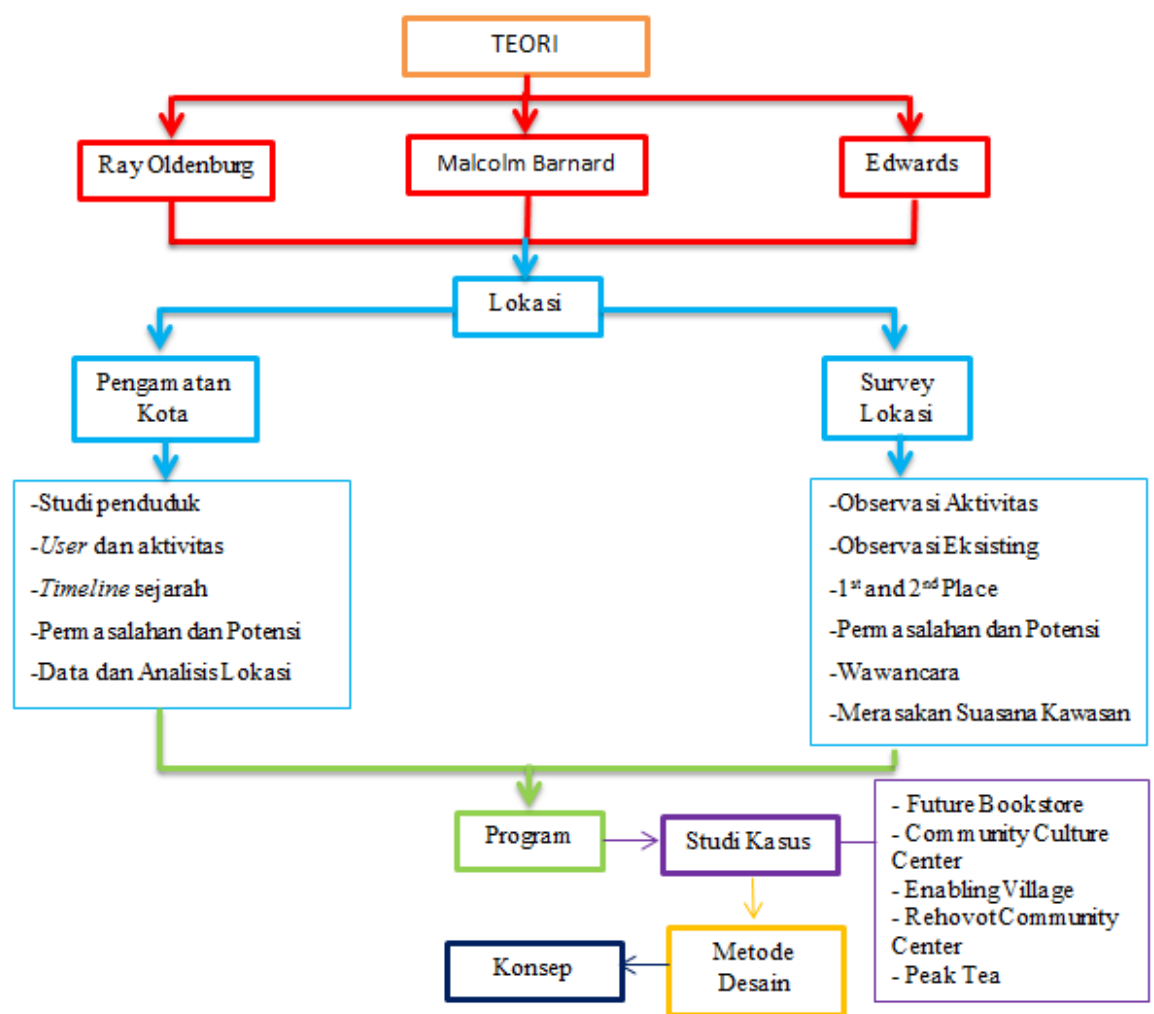

Gambar 1. Alur metode penelitian

Sumber: penulis, 2020

Berdasarkan pengamatan di lapangan, berikut merupakan diagram persentase aktivitasaktivitas yang terjadi di Senen dari Pagi hingga Dini hari dan Mapping kegiatan yang terdapat di Senen :
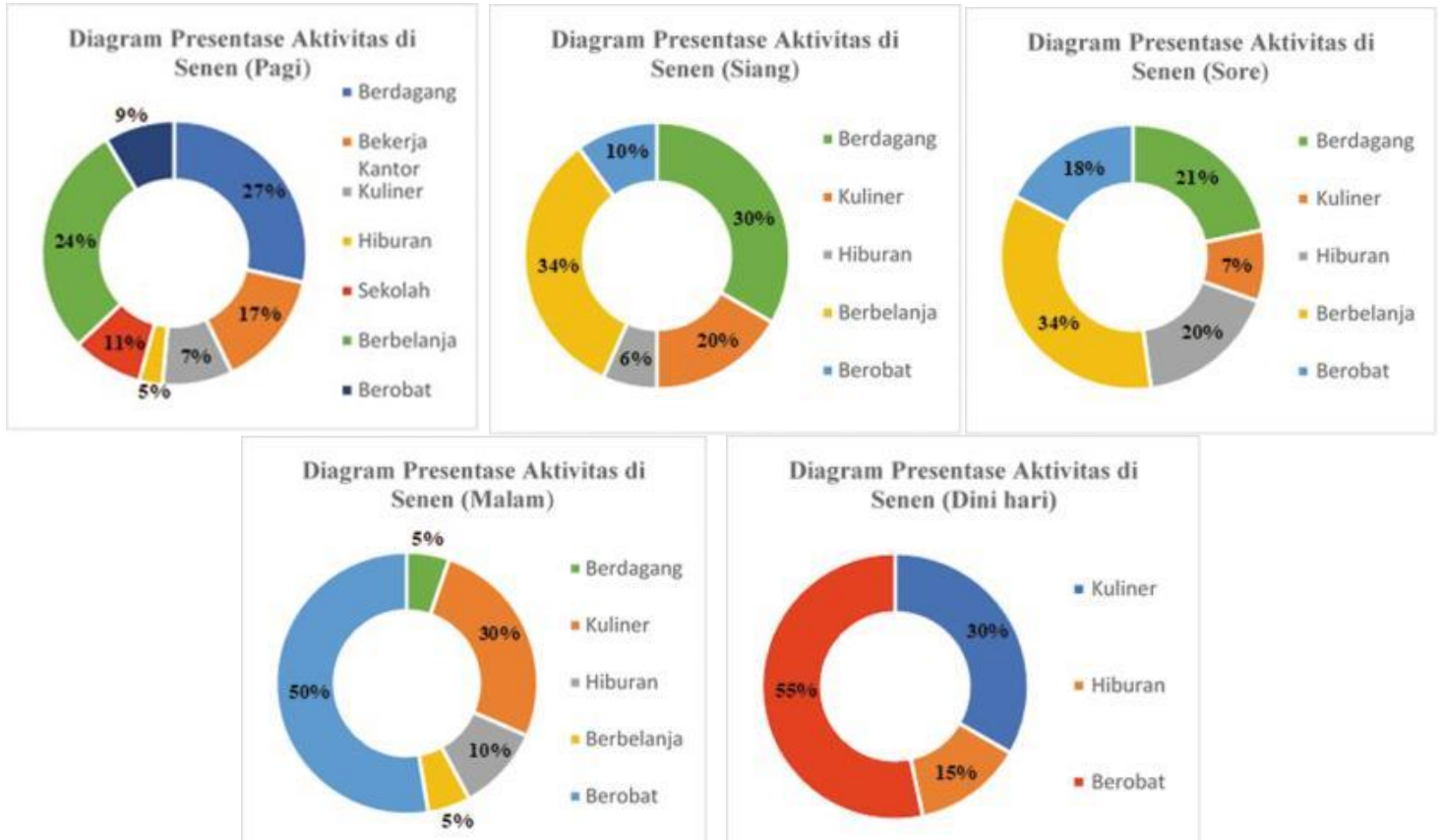

Diagram 1. Diagram Presentase Aktivitas di Senen (Pagi-Dini hari)

Sumber: penulis, 2020 
Dari data diatas, dapat disimpulkan bahwa Senen didominasi oleh kegiatan berdagang, bekerja, berobat, dan berbelanja.

a. Aktivitas Masyarakat Kelurahan Senen (Pagi-Subuh)

b. Masyarakat lebih banyak melakukan aktivitas pada pagi sampai sore hari yaitu berdagang dan berbelanja. Sesuai dengan identitas Kawasan Senen sendiri yaitu area perdagangan / jasa. Lalu diikuti oleh masyarakat lebih banyak berkunjung ke Kawasan Senen untuk berobat pada malam hari. Sedikitnya masyarakat yang pergi ke Senen untuk kuliner menjadi permasalahan yang dapat diangkat nantinya. Serta kurangnya tempat hiburan dan ruang sosial bagi masyarakat terlihat jelas pada data diagram persentase diatas.

c. Berobat menjadi destinasi utama pada saat malam hari

d. Kelurahan Senen tidak memiliki hiburan / tempat yang dapat dikunjungi pada saat malam hari selain Plaza Atrium. Dikarenakan Pasar Senen hanya buka sampai jam 17.30 WIB, maka lalu lintas pada malam hari di sekitar Senen tergolong sepi. Kecuali pada jalan Kwini I dimana letak RSUD Gatot Subroto berada.

e. Tidak Adanya Hiburan di Malam Hari

f. Di Kawasan Senen hanya terdapat Plaza Atrium sebagai tempat hiburan yang dapat dijadikan destinasi untuk menghilangkan stress / nongkrong.

g. Banyak masyarakat yang berusia produktif yang tinggal di Senen

h. Dari data yang dapat menganalisa bahwa masyarakat yang produktif yang tinggal di Senen sangat banyak dan memiliki potensi untuk dikembangkan menjadi pribadi yang kreatif, dan tidak hanya terpaku pada berdagang.

\section{DISKUSI DAN HASIL}

\section{Hasil Kajian}

Berdasarkan dari kajian teori oleh Ray Oldenburg dikatakan bahwa sebuah tempat dapat dikatakan sebagai Third Place jika mengusung konsep yang dapat membuat masyarakat dapat saling berinteraksi dan merasa nyaman tanpa adanya perbedaan strata sosial.Berdasarkan dari kajian teori oleh Malcolm Barnard mengatakan bahwa fashion/pakaian dapat menjadi sebuah alat komunikasi yang baik secara verbal maupun non-verbal yang nantinya akan disampaikan ke setiap pribadi manusia sebagai perantara untuk membuat pribadi manusia itu sendiri berubah menjadi kearah yang lebih positif dan melatih pola berfikir manusia untuk lebih kreatif. Serta berdasarkan Edwards menurut teorinya dengan berbelanja kita sebagai pribadi manusia dapat menghilangkan rasa perasaan negatif yaitu stres/perasaan cemas.

Sehingga proyek ini dibuat dengan desain konsep bangunan yang terbuka atau welcoming sehingga masyarakat dari berbagai kalangan dapat tertarik untuk masuk beraktivitas di dalam proyek. Dan dimasukan konsep fashion dimana fashion digunakan sebagai media untuk masyarakat berkomunikasi serta berinteraksi satu sama lain tanpa adanya Batasan juga sebagai salah satu sarana masyarakat dapat mengekspresikan kreatifitas mereka ke masyarakat luas yang akan berdampak positif. Pakaian ekonomis merupakan salah satu konsep yang dapat diambil dari Kawasan Senen karena terdapat Pasar Senen yang merupakan pusat dari masyarakat yang ingin berbelanja pakaian ekonomis saja akan tetapi kurangnya fasilitas yang memadai sehingga proyek ini bertujuan untuk menunjang masyarakat khususnya sebagai penggemar pakaian ekonomis/fashion. 


\section{Konsep}

Melalui analisa tapak sekitar, sirkulasi dan aktivitas:

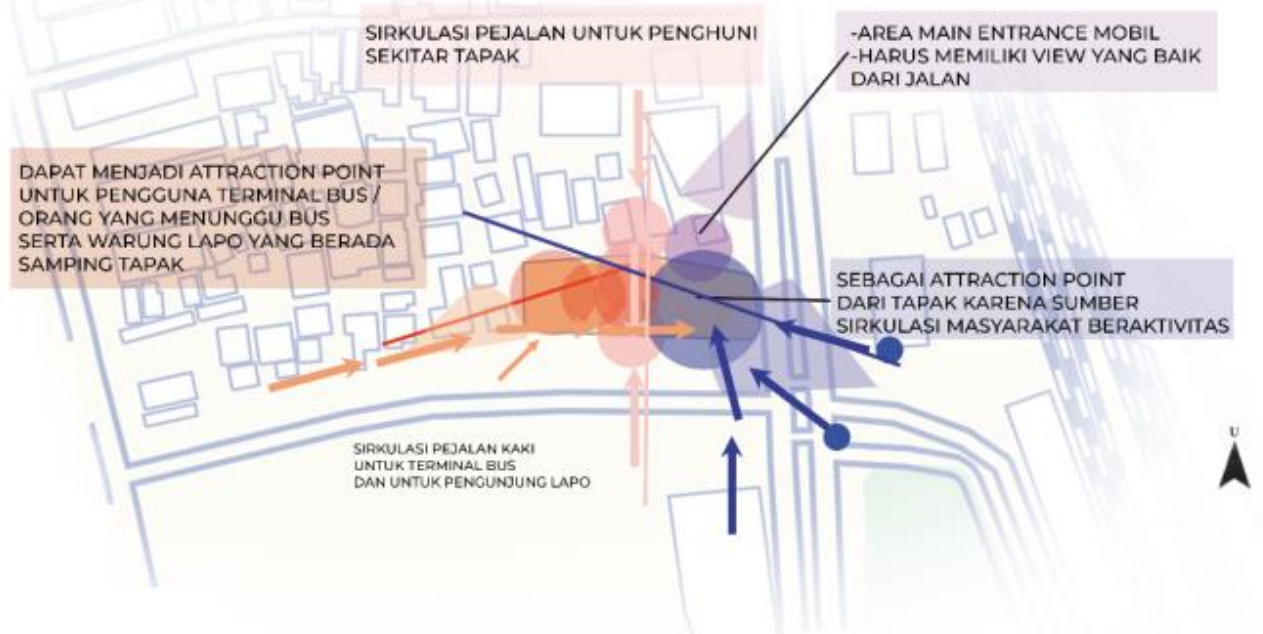

Gambar 2. Analisa Tapak

Sumber: penulis, 2020

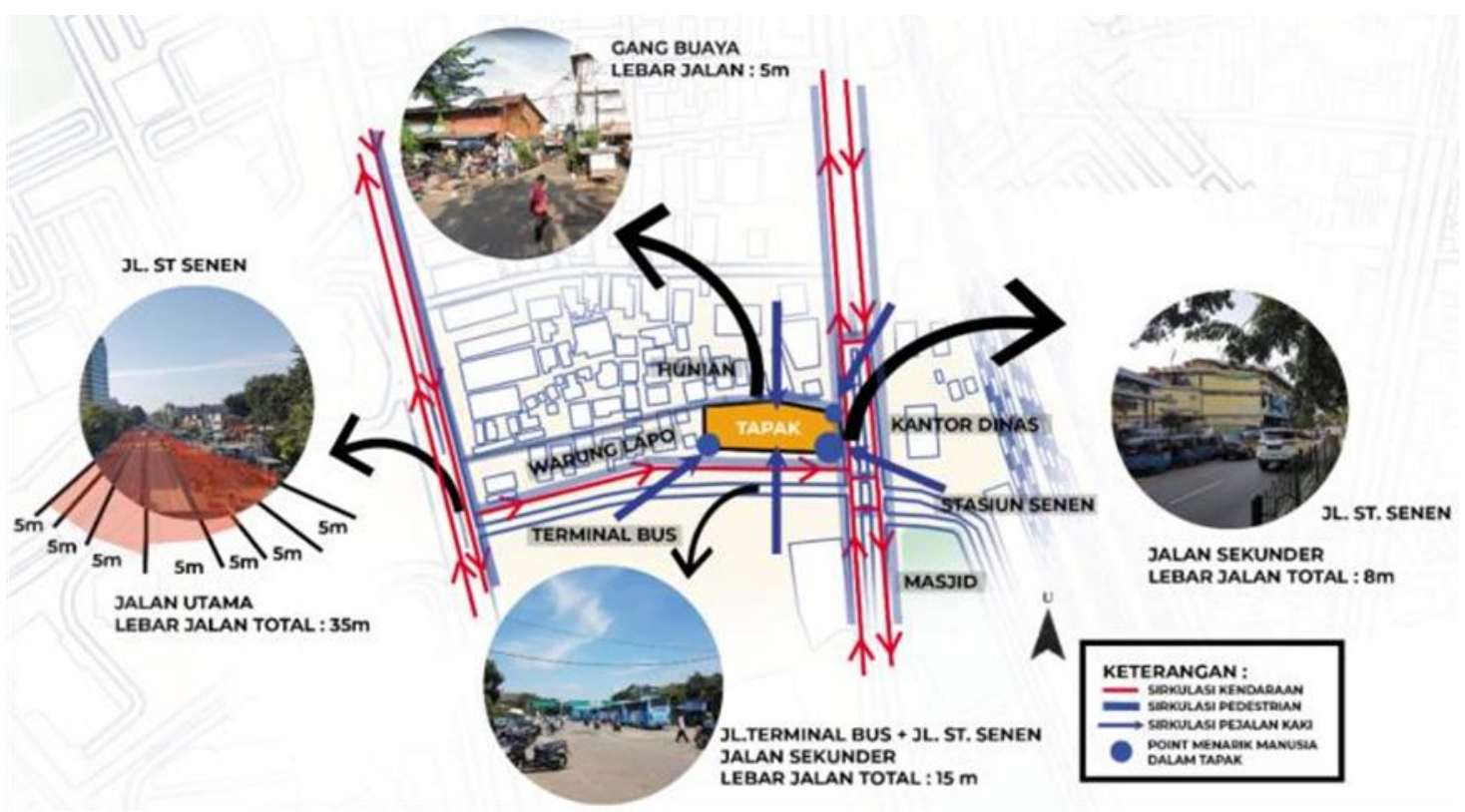

Gambar3. Analisa Sirkulasi dan Orientasi Sumber: penulis, 2020

Pasar Senen merupakan salah satu bangunan yang bersejarah untuk masyarakat Senen dan kota Jakarta. Pasar Senen saat ini dikenal sebagai pusat thrift di Jakarta. Dimana thrift merupakan masyarakat yang mengoptimalkan uang untuk berbelanja yang disebut belanja hemat. Belanja hemat disini bukan menghimbau masyarakat untuk tidak membeli pakaian namun bagaimana berbelanja secara ekonomis. Ekonomis berarti masyarakat dihimbau untuk mengerti \& mempelajari apa yang dibeli dan apa yang dilihat. Proyek ini bertujuan untuk mengurangi kejenuhan penghuni pasar senen dalam kegiatan berniaganya sehari-hari juga untuk memfasilitasi kebutuhan pengguna jasa di stasiun bus senen. maka dirancanglah proyek Fasilitas Penggemar Pakaian Ekonomis. 
Keberadaan proyek ini selain menunjang thriftshop (toko pakaian ekonomis) pasar senen yang sudah dikenal oleh masyarakat juga menambahkan berbagai aktivitas yang ada di sekitarnya agar semakin bertambah ramai dan hidup. Karena proyek ini ditujukan bagi seluruh lapisan masyarakat pengguna, menjawab esensi dari third place sebagai ruang netral bagi seluruh lapisan masyarakat senen khususnya dan masyarakat kota Jakarta umumnya. Konsep fashion /pakaian ekonomis pada program aktivitas yang akan disajikan nantinya agar menjadi sebuah wadah third place yang baik tidak hanya mengenai pakaian saja akan tetapi terdapat juga berbagai jenis aksesoris seperti tas, sepatu, topi , pernak Pernik dan lain-lain. Masyarakat akan dihimbau untuk mempelajari sejarah/mengerti makna makna dari fashion melalui galeri/kumpulan komunitas.

Desain bangunan pada awalnya diambil dari hasil/kesimpulan analisis tapak yaitu pada tapak terpilih memiliki lima titik penting yang merupakan titik sirkulasi manusia maupun mobil. Dari lima titik itu memberikan bentuk cekungan kedalam yang tandanya sebagai titik penerima manusia. Pada titik tengah mengahdap ke Jl. Terimnal Bus Senen merupakan titik penting dari bangunan. Setelah itu bangunan yang telah menyatu pada site dikombinasikan dengan konsep fashion yang tidak luput dari human body/tubuh manusia dan pakaian. Dimana warna kuning pada skema gambar melambangkan tubuh manusia yang sedang dilindungi oleh warna putih pada skema yang diibaratkan sebagai pakaian yang dipakai manusia.

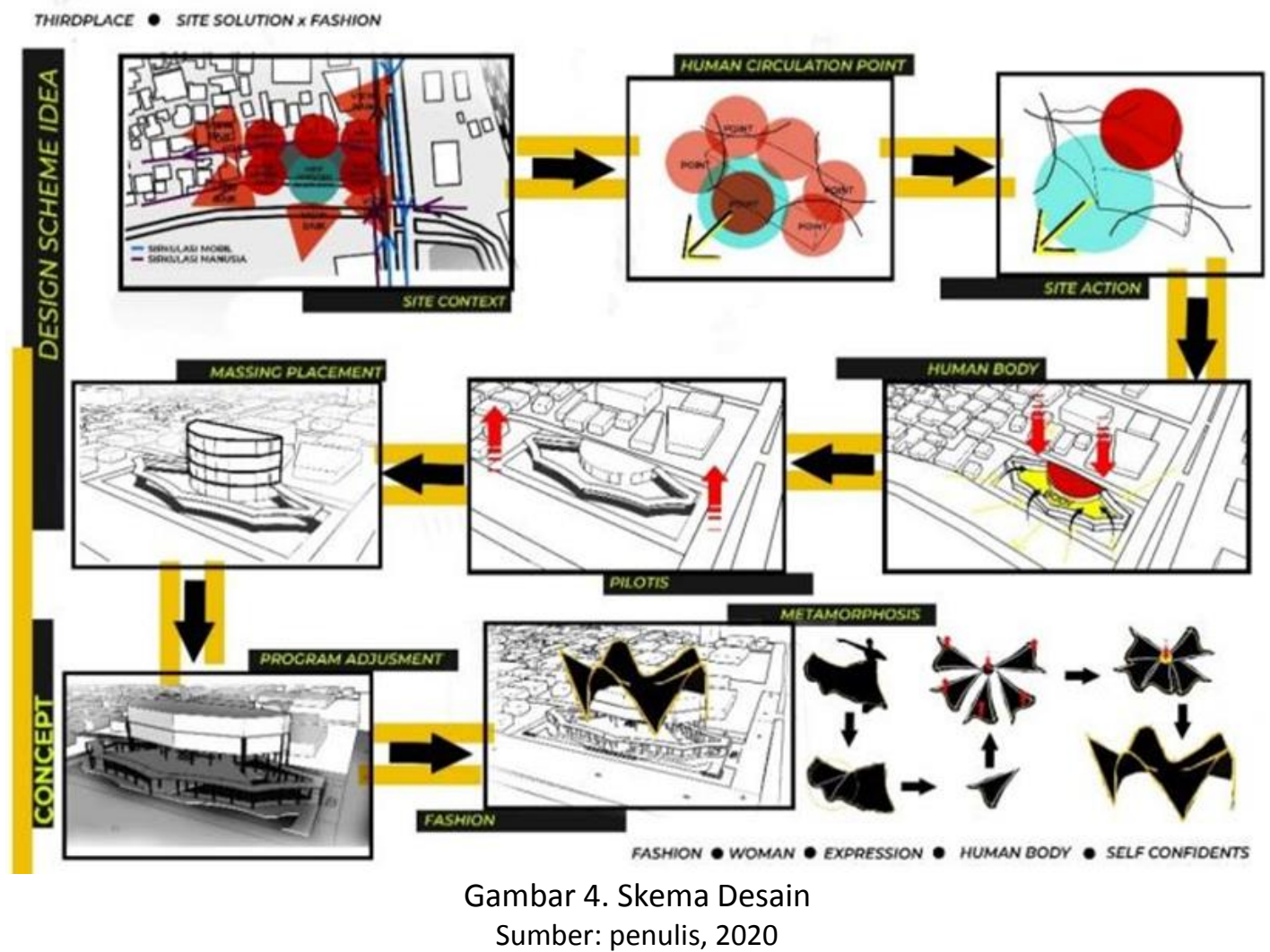

Program disesuaikan dengan aktivitas-aktivitas yang biasa dilakukan di sekitar kawasan dan juga dari kebutuhan, serta luasan didasarkan oleh analisa-analisa data tapak sekitar, mulai dari aktivitas sehari-hari pengunjung atau masyarakat sekitar dan juga lokasi kawasan. Program proyek antara lain Lantai 1 berupa Pop-Up Fashion Galleria, lantai 2 berupa Food Thrift Market, lantai 3 berupa Thrift Collaborative Space, lantai 4 berupa Thrift Galleria \& Exhibition dan lantai B1 untuk area utilitas. 


\section{Pop-Up Fashion Galleria}

Pop-Up Fashion Galleria pada lantai 1 memiliki konsep area yang terbuka dimana masyarakat dapat beraktivitas bebas akan tetapi tetap mengacu kepada tema yaitu fashion. Pada lantai ini terdapat berbagai acara mengenai fashion yang berganti-ganti. Nama Pop-up disini dikarenakan tempat ini dapat dijadikan tempat untuk berbagai acara baik yang muncul secara tiba-tiba maupun acara yang telah direncanakan sebelumnya seperti bazar, pameran, maupun sejenisnya.

\section{Food Thrift Market}

Area lantai 2 ini dinamakan lantai Food Thrift Market dimana area yang dominan communal commersial merupakan tempat pasar makanan dengan konsep thrifting. Masyarakat dapat membeli makanan dengan harga yang sangat terjangkau untuk semua kalangan masyarakat serta terdapat performance dari seniman jalanan Senen yang telah meredup.

\section{Thrift Collaborative Space}

Lantai 3 ini meruakan lantai komunitas thrift yang terdapat workshop berupa Thriftshop yang dinamakan lantai Thrift Collaborative Space dimana masyarakat dari segala kalangan tidak hanya berbelanja barang-barang dengan harga ekonomis / terjangkau untuk melepas stress akan tetapi mempelajari juga silsilah sejarah / makna dari barang-barang yang mereka beli. Selain itu masyarakat juga dihimbau untuk mengikuti talkshow yang bersifat sosial agar masyarakat dapat berinteraksi dan berkomunikasi satu sama lain dengan perantara fashion.

\section{Thrift Galleria \& Exhibition}

Lantai 4 ini berisikan tempat untuk mempelajari budaya dan cara mendesain yang berbau fashion. Masyarakat dihimbau untuk mengerti dan mempelajari fashion dengan melihat pameran serta diajarkan untuk mengenal bagaimana proses cara mendesain yang baik dan benar. Dari sini masyarakat dapat berinteraksi secara bebas satu sama lain dan terdapat juga tempat lelang yang lelang tersebut bertujuan untuk didonasikan ke masyarakat-masyarakat kurang mampu.

\begin{tabular}{|l|l|c|}
\hline \multicolumn{1}{|c|}{ ZONE } & \multicolumn{1}{|c|}{ PROGRAM } & LUASAN \\
\hline $\begin{array}{l}\text { THRIFT } \\
\text { GALLERIA } \\
\text { EXHIBITION } \\
\text { (ENTERTAIN } \\
\text { COMMUNAL) }\end{array}$ & $\begin{array}{l}\text { TEMPORARY STREET } \\
\text { PERFORMANCE SPOT }\end{array}$ & $136 \mathrm{~m}^{2}$ \\
\hline $\begin{array}{l}\text { COMMUNAL } \\
\text { AREA } \\
\text { COMMERCIAL }\end{array}$ & FOOD THRIFT MARKET & \\
\hline EAT AREA & \\
\hline COMMUNAL & TANGGA & $757 \mathrm{~m}^{2}$ \\
& EATING BRIDGE & \\
& KORIDOR & $40 \mathrm{~m}^{2}$ \\
& & $60 \mathrm{~m}^{2}$ \\
& & $152 \mathrm{~m}^{2}$ \\
& R. JANITOR & \\
\hline SERVICE & TOILET & $6 \mathrm{~m}^{2}$ \\
& FOOD LOADING & $50 \mathrm{~m}^{2}$ \\
& R. PANEL & $18 \mathrm{~m}^{2}$ \\
& GUDANG & $9 \mathrm{~m}^{2}$ \\
\hline TOTAL & R. SAMPAH & $10 \mathrm{~m}^{2}$ \\
& & $10 \mathrm{~m}^{2}$ \\
\hline
\end{tabular}

\begin{tabular}{|c|c|c|}
\hline ZONE & PROCRAM & LUASAN \\
\hline $\begin{array}{l}\text { THRIFT } \\
\text { GALLERIA } \\
\text { EXHIBITION } \\
\text { (ENTERTAIN } \\
\text { COMMUNAL) }\end{array}$ & $\begin{array}{l}\text { POP UP SQUARE } \\
\text { (FASHION SHOW \& } \\
\text { FASHION ART SHOW) } \\
\text { MINI THRIFT CINEMA } \\
\text { R. MEKANIKAL CINEMA } \\
\text { R. KONTROL } \\
\text { CUDANC } \\
\text { FASHION GALLERIA }\end{array}$ & $\begin{array}{l}355 m^{2} \\
170 m^{2} \\
177 m^{2}\end{array}$ \\
\hline $\begin{array}{l}\text { COMMUNAL } \\
\text { AREA }\end{array}$ & $\begin{array}{l}\text { KORIDOR } \\
\text { COFFEE SHOP } \\
\text { FOOD STAND }\end{array}$ & $\begin{array}{l}296 m^{2} \\
50 m^{2} \\
50 m^{2}\end{array}$ \\
\hline SERVICE & $\begin{array}{l}\text { R.JANITOR } \\
\text { TOILET } \\
\text { MUSHOLLA } \\
\text { LOADING DOCK } \\
\text { R.PANEL } \\
\text { GUDANC } \\
\text { R.SAMPAH }\end{array}$ & $\begin{array}{l}6 m^{2} \\
50 m^{2} \\
8 m^{2} \\
18 m^{2} \\
9 m^{2} \\
10 m^{2} \\
10 m^{2}\end{array}$ \\
\hline TOTAL & & $1395 m^{2}$ \\
\hline
\end{tabular}




\begin{tabular}{|l|l|c|}
\hline \multicolumn{1}{|c|}{ ZONE } & \multicolumn{1}{|c|}{ PROGRAM } & LUASAN \\
\hline $\begin{array}{l}\text { COMMUNAL } \\
\text { AREA } \\
\text { COMMERCIAL }\end{array}$ & $\begin{array}{l}\text { THRIFTSHOP SOCIETY HALL } \\
\text { THRIFTSHOP EXHIBITION }\end{array}$ & $215 \mathrm{~m}^{2}$ \\
& & $215 \mathrm{~m}^{2}$ \\
\hline $\begin{array}{l}\text { COMMUNAL } \\
\text { AREA } \\
\text { OPEN } \\
\text { SPACE }\end{array}$ & MEETING SPACE & \\
& R. KOMUNITAS & $30 \mathrm{~m}^{2}$ \\
\hline COMMUNAL & & $30 \mathrm{~m}^{2}$ \\
AREA & TANGCA & \\
& & \\
\hline SERVICE & KANTOR PENGELOLA & $40 \mathrm{~m}^{2}$ \\
& GUDANG THRIFTSHOP & \\
& JANITOR & $35 \mathrm{~m}^{2}$ \\
& TOILET & $36 \mathrm{~m}^{2}$ \\
& R. PANEL & $6 \mathrm{~m}^{2}$ \\
& GUDANG & $50 \mathrm{~m}^{2}$ \\
& LOADING BARANG & $9 \mathrm{~m}^{2}$ \\
& R. AHU & $10 \mathrm{~m}^{2}$ \\
& & $15 \mathrm{~m}^{2}$ \\
\hline TOTAL & & $10 \mathrm{~m}^{2}$ \\
\hline
\end{tabular}

\begin{tabular}{|c|c|c|}
\hline ZONE & PROGRAM & LUASAN \\
\hline $\begin{array}{l}\text { THRIFT } \\
\text { GALLERIA } \\
\text { EXHIBITION } \\
\text { (ENTERTAIN } \\
\text { COMMUNAL) }\end{array}$ & $\begin{array}{l}\text { LELANG SPACE } \\
\text { DESIGN FASHION STUDIO } \\
\text { FASHION ART WALLS }\end{array}$ & $\begin{array}{l}155 m^{2} \\
350 m^{2} \\
100 m^{2}\end{array}$ \\
\hline $\begin{array}{l}\text { COMMUNAL } \\
\text { AREA }\end{array}$ & OUTDOOR SPACE & $30 m^{2}$ \\
\hline SERVICE & $\begin{array}{l}\text { R. PANEL } \\
\text { R. AHU } \\
\text { TOILET } \\
\text { LOADING BARANG } \\
\text { JANITOR } \\
\text { GUDANG }\end{array}$ & $\begin{array}{l}9 m^{2} \\
10 m^{2} \\
50 m^{2} \\
16 m^{2} \\
6 m^{2} \\
10 m^{2}\end{array}$ \\
\hline TOTAL & & $1231 \mathrm{~m}^{2}$ \\
\hline
\end{tabular}

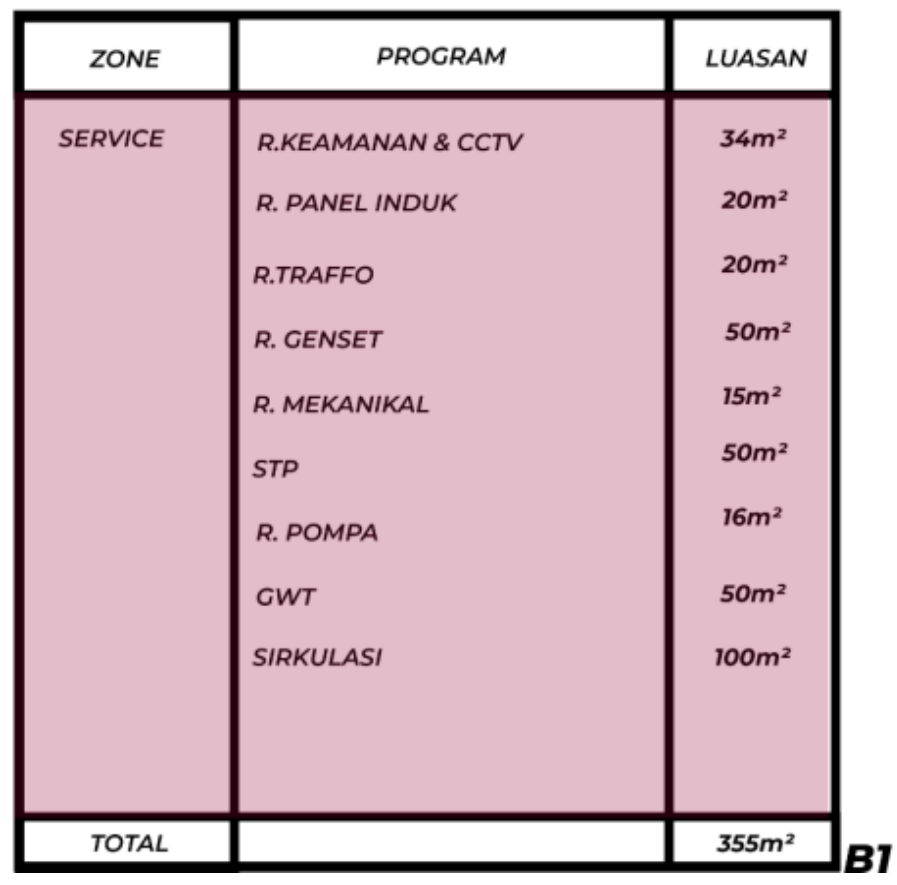

Gambar 5. Tabel Program

Sumber: penulis, 2020

Tapak berada di Jl. St Senen, Senen, Jakarta Utara. Tapak ini memiliki beberapa keunggulan seperti dekat dengan Pasar Senen, moda transportasi seperti (Stasiun Senen, Terminal Bus Senen, Transjakarta), pusat aktivitas masyarakat dan juga keunikan dan identitas kawasan itu sendiri. Proyek terancang memiliki KDB 1395 m², KLB 5269 m², KDH 752 m², KTB 1724 m² dan tinggi bangunan 4 lantai. 


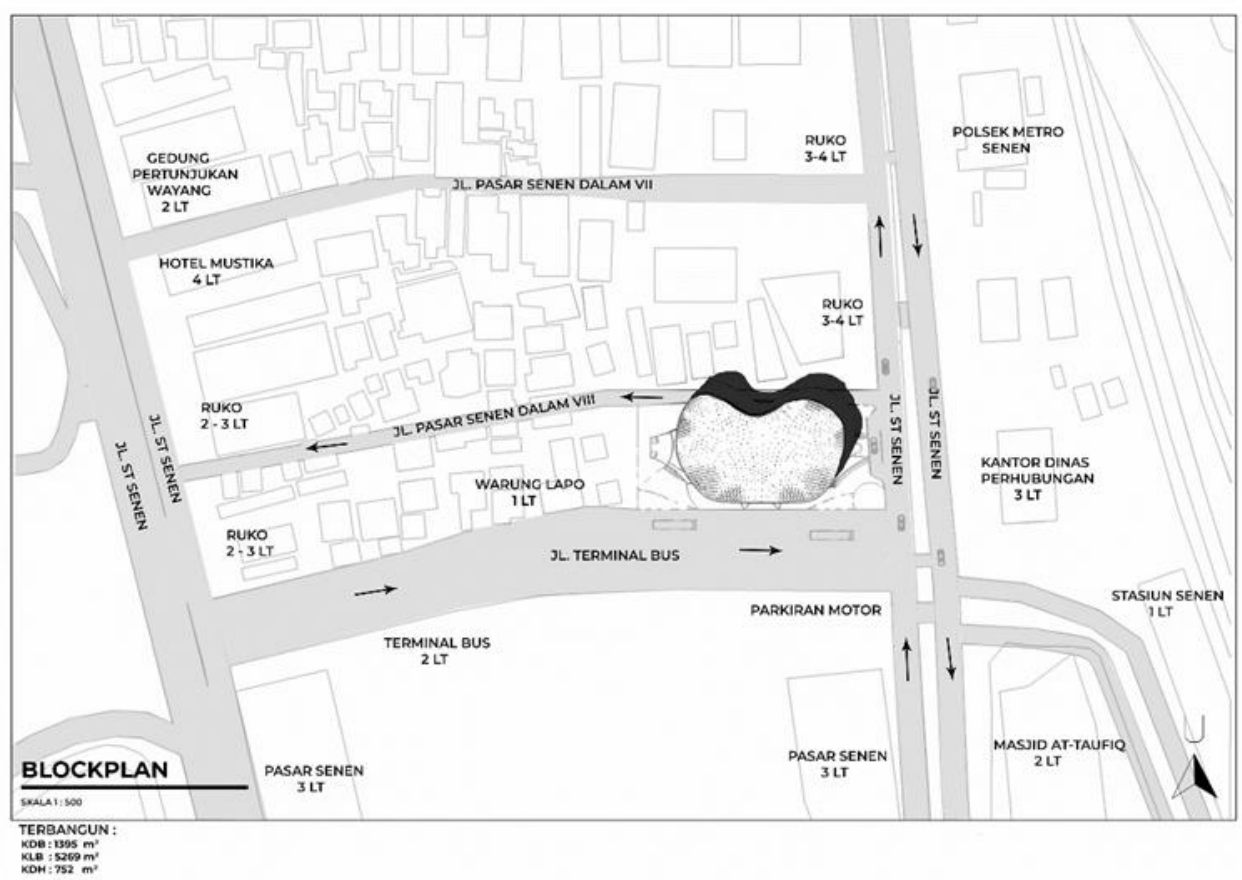

Gambar 6. Blockplan

Sumber: penulis, 2020

\section{KESIMPULAN DAN SARAN}

\section{Kesimpulan}

Proyek Fasilitas Penggemar Pakaian Ekonomis merupakan wadah penunjang fungsi dari Pasar Senen yang merupakan pusat thrift di Jakarta. Yang dimana thrift diartikan bagaimana masyarakat memakai uang secara ekonomis. Ekonomis pada proyek ini ditujukan kepada masyarakat Senen yang tadinya mayoritas aktivitas sehari-harinya hanya berdagang tanpa mengetahui arti dari pakaian yang diperdagangkan menjadi lebih dapat menghargai nilai, sejarah, dan esensi dari setiap pakaian yang diperjual belikan. Pakaian yang dimaksud tidak hanya sekedar baju atau celana melainkan semua atribut yang dipakai manusia sehari-hari seperti: tas, topi, sepatu, aksesoris dan lain-lain. Aktivitas ini memicu komunitas-komunitas thrift / pemburu pakaian ekonomis terbentuk sehingga memicu terjadinya proses timbal balik atau sebuah interaksi yang mengacu kepada konsep third place. Dimana masyarakat dapat berinteraksi dan berkumpul secara seksama tanpa adanya batasan atau perbedaan.

Kemudian selain proyek ini memicu masyarakat untuk berinteraksi dan berkumpul juga mengedukasi masyarakat Senen serta mengasah kreatifitas dari program-program yang diambil berdasarkan survey kebutuhan masyarakat sekitar tapak seperti Thrift Galleria \& Exhibition yang merupakan tempat masyarakat yang datang untuk melihat kreatifitas seni dari pakaian-pakaian bersejarah yang dibuat oleh masyarakat Senen yang kemudian akan di pamerkan ke pengunjung. Selain itu terdapat Fashion Gallery Studio tempat untuk masyarakat berlatih bersama komunitas komunitas thrift.

Semua ini dibungkus dalam sebuah wadah bangunan yang didesain berdasarkan analisa tapak dan konsep fashion / pakaian yang kita ketahui fashion / pakaian tidak luput dari human body atau tubuh manusia. Kemudian dipadukan dengan konsep Open Architecture yang artinya terbuka untuk siapa saja dan tidak ada perbedaan antar golongan masyarakat (netral) sehingga membuat proyek ini merupakan jawaban dari kebutuhan Third Place untuk masyarakat kawasan Senen maupun masyarakat kota Jakarta. 


\section{Saran}

Diharapkan proyek ini dapat menjadi pemicu perkembangan perekonomian Senen dan juga menjadi sarana yang nyaman dan bagi semua golongan masyarakat untuk bersosialisasi, berkumpul, dan berinteraksi satu sama lain tanpa adanya perbedaan.

\section{REFERENSI}

Barnard, M. (1996). Fashion as Communication. New York : Routledge

Edwards. (1993). Measuring Compulsive Buying Behaviour. Hungary : Eötvös Loránd University Gehl, J. (1971). Life Between Buildings. California: Island Press

Morisson, A. (2018). A Typology of Places in the Knowledge Economy: Towards the Fourth Place.

Oldenburg, R. (1997). The Great, Good Place. Cambridge : Da Capro Press 
